\title{
Formulation and Evaluation of Swelling Restricted Matrix Tablet Containing Metformin Hcl
}

\author{
Deepu $\mathrm{S}^{1}$, Dr. (Sr.) Molly Mathew ${ }^{2}$, Shamna M S \\ ${ }^{I}$ Assistant Professor, Pharmaceutics, Mar Dioscorus College of Pharmacy Trivandrum Kerala India. \\ ${ }_{2}^{2}$ Principal, Pharmacognosy, Malik Deenar College of Pharmacy, Kasaragod Kerala, India. \\ ${ }^{3}$ Assistant Professor, Pharmacy Practice, Mar Dioscorus College of Pharmacy, Trivandrum, Kerala India.
}

\begin{abstract}
Conventional drug delivery system and is known to provide an immediate release of drug, an alternative to administration of another dose is to use a dosage form that will provide sustained drug release. Metformin Hcl was formulated as restricted swelling matrix tablet by using HPMC K100 and CMC in ratio of 50:50 in order to obtain a sustained release formulation. Matrix tablets containing 500mg of metformin were prepare by direct compression method. From the formulations MFH 12 was selected and given partial coating with cellulose acetate $5 \%$ solution in acetone (MFH 13 \& MHF14) to restrict the swelling and hence to retard its release. The drug polymer ration influenced the release of drug from the formulations. An increase in polymer decreased the drug release. F13 partially coated swelling matrix tablet further retarded the release of drug. Formulation F13 with drug polymer (HPMC K100M and CMC) ratio (500:125:125) has shown promising results as per USP test I requirements.
\end{abstract}

Keywords: Cellulose acetate, swelling restricted, CMC, HPMC K100M, Metformin Hcl.

\section{INTRODUCTION}

Metformin $\mathrm{HCl}$ is a biguanide oral antihyperglycemic (antidiabetic) agent. It is used as monotherapy as an adjunct to diet and exercise for the management of type 2 (non-insulin dependent) diabetes mellitus in patients whose hyperglycaemia cannot be controlled by diet alone. It is freely soluble in water. A traditional oral multiple release formulation releases the drug with undesirable peaks and troughs. These drawbacks can be overcome by designing a suitable sustained release metformin $\mathrm{HCl}$ preparation ${ }^{1,2}$.

Metformin shows incomplete absorption from the gastrointestinal tract and absolute bioavailability in the range of $50-60 \%$ with relatively short plasma half-life of $1.5-4.5 \mathrm{Hr}$. oral absorption of metformin is within the upper part of intestine i.e. duodenum, jejunum and to a lesser extend in ileum ${ }^{3}$. Therefore the prepared tablets must initiate release of drug from stomach and complete it in jejunum. Hence a controlled release formulation that would maintain plasma levels from $12-15$ Hrs. would be sufficient for giving once daily dosage forms $\mathrm{s}^{4,5}$.

An alternative to conventional dose is to use a dosage form that will provide sustained drug release, and therefore, maintain plasma drug concentrations. Controlled release formulations are much desirable and preferred for such therapy because they offer better patient compliance, maintain uniform drug levels, reduced dose and side effects and increased margin of safety for high potency drugs ${ }^{2,3}$

The term "controlled release" has been associated with those systems which release their active principle at a predetermined rate. Physician can achieve certain desirable therapeutic benefits by prescribing controlled release dosage forms; since the frequency of drug administered is reduced the patient compliance gets improved $^{2}$.

Metformin is a first line drug of choice for the treatment of type II diabetes acts by decreasing hepatic glucose output and peripheral insulin resistance. It can be given to the patients with overweight and obese and with normal kidney function 5 . 


\section{MATERIALS AND METHODS}

1. Materials: Metformin hydrochloride was obtained as a gift sample from Dr Reddys Laboratories Ltd, Methocel was obtained as gift sample from Colorcon Asia Pvt Ltd, Carboxy methyl cellulose, CAP, and Plasdone was obtained from Ashland Inc. Other materials such as Magnesium stearate, MCC, Aerosil etc. were purchased and were of procured from SD fine, Mumbai.

2. Methods: Table 1 enlist the number of different excipients with its ratio of mixing with different polymers, MCC was used as filler ${ }^{3}$. Matrix tablets containing $500 \mathrm{mg}$ of metformin were prepare by direct compression method ${ }^{6}$. Drug and excipients were shifted through mesh 40 and blended for 15 minutes using octagonal blender. Magnesium stearate was shifted through mesh 80 and transferred to blender and further mixed for 5 minutes. Above lubricated blend was compressed in 16 station Cadmach rotary tablet punching machine (M/S Cadmach machinery private Ltd, Ahmadabad) using caplet shape12 size punches. . Before compression the surfaces of the dies and punches were lubricated with magnesium stearate ${ }^{7}$

\section{PREPERARTION OF SWELLING RESTRICTED MATRIX TABLETS}

From the formulations showed in table 1 MFH 12 was selected and given partial coating with cellulose acetate $5 \%$ solution in acetone ( MFH 13 \& MHF14) to restrict the swelling and hence to retard its release.

\begin{tabular}{|c|c|c|c|c|c|c|c|c|c|c|c|c|c|}
\hline SlNo & $\begin{array}{l}\text { INGREDIENT } \\
\mathrm{S}\end{array}$ & $\begin{array}{l}\text { MFH } \\
1\end{array}$ & $\begin{array}{l}\text { MFH } \\
2\end{array}$ & MFH 3 & MFH 4 & MFH 5 & $\begin{array}{l}\text { MFH } \\
6\end{array}$ & MFH 7 & $\begin{array}{l}\text { MFH } \\
8\end{array}$ & $\begin{array}{l}\text { MFH } \\
9\end{array}$ & MFHl0 & $\begin{array}{l}\text { MFHl } \\
1\end{array}$ & MFHl2 \\
\hline 1 & METFORMIN & 500 & 500 & 500 & 500 & 500 & 500 & 500 & 500 & 500 & 500 & 500 & 500 \\
\hline 2 & HPMC K4M & 150 & 200 & 250 & $\mathrm{X}$ & $\mathrm{X}$ & $\mathrm{X}$ & $\mathrm{X}$ & $\mathrm{X}$ & $\mathrm{X}$ & $\mathrm{X}$ & $\mathrm{X}$ & $\mathrm{X}$ \\
\hline 3 & HPMC K15M & $\mathrm{X}$ & $\mathrm{X}$ & $\mathrm{X}$ & 150 & 200 & 250 & $\mathrm{X}$ & $\mathrm{X}$ & $\mathrm{X}$ & $\mathrm{X}$ & $\mathrm{X}$ & $\mathrm{X}$ \\
\hline 4 & HPMC K100M & $\mathrm{X}$ & $\mathrm{X}$ & $\mathrm{X}$ & $\mathrm{X}$ & $\mathrm{X}$ & $\mathrm{X}$ & 150 & 200 & 250 & 200 & 150 & 125 \\
\hline 5 & $\mathrm{CMC}$ & $\mathrm{X}$ & $\mathrm{X}$ & $\mathrm{X}$ & $\mathrm{X}$ & $\mathrm{X}$ & $\mathrm{X}$ & $\mathrm{X}$ & $\mathrm{X}$ & $\mathrm{X}$ & 50 & 100 & 125 \\
\hline 6 & LACTOSE & 200 & 150 & 100 & 200 & 150 & 100 & 200 & 150 & 100 & 100 & 100 & 100 \\
\hline 7 & PVP $10 \%$ & q.s & q.s & q.s & q.s & q.s & q.s & q.s & q.s & q.s & q.s & q.s & q.s \\
\hline 8 & Mg Stearate & q.s & q.s & q.s & q.s & q.s & q.s & q.s & q.s & q.s & q.s & q.s & q.s \\
\hline 9 & Aerosil & q.s & q.s & q.s & q.s & q.s & q.s & q.s & q.s & q.s & $\mathrm{q} . \mathrm{s}$ & q.s & q.s \\
\hline \multicolumn{2}{|c|}{ Total Weight (mg) } & 850 & 850 & 850 & 850 & 850 & 850 & 850 & 850 & 850 & 850 & 850 & 850 \\
\hline
\end{tabular}

Table 1: List of ingredients with its formulation

\section{Preparation of Standard Curve for Metformin}

\section{Preparation of standard stock solution:}

Metformin HCL (100.0mg) was accurately weighed and transferred into a 100ml volumetric flask and dissolved in $50 \mathrm{ml}$ of distilled water. The volume was make up to $100 \mathrm{ml}$ using distilled water to obtain a standard stock solution of drug concentration of $1000 \mu \mathrm{g} / \mathrm{ml}$. From this Standard stock solution of metformin $100 \mu \mathrm{g} / \mathrm{ml}$ was prepared by pipetting $10 \mathrm{ml}$ of stock solution to a $100 \mathrm{ml}$ volumetric flask and making it up to $100 \mathrm{ml}$ with distilled water.

\section{Determination of wavelength of maximum amplitude $\left(\mathrm{D}^{2}\right.$ value) of Metformin HCL.}

$10 \mathrm{ml}$ of the above solution was diluted to $100 \mathrm{ml}$ with the same solvent to get a concentration of $10 \mu \mathrm{g} / \mathrm{ml}$. The UV spectrum of final solution was scanned in the range of $200-400 \mathrm{~nm}$ against distilled water as blank. The $\lambda_{\max }$ was found at $233.8 \mathrm{~nm}$.

\section{Metformin HCL STD Curve:}

$1 \mathrm{ml}$ of the standard stock solution was taken and diluted to $10 \mathrm{ml}$ with distilled water $(100 \mu \mathrm{g} / \mathrm{ml})$. From the above solution $0.2,0.4,0.6,0.8$ and $1 \mathrm{ml}$ was pipette out and diluted to $10 \mathrm{ml}$ with distilled water to give the final concentration of $2,4,6,8$ and $10 \mu \mathrm{g} / \mathrm{ml}$ respectively. 


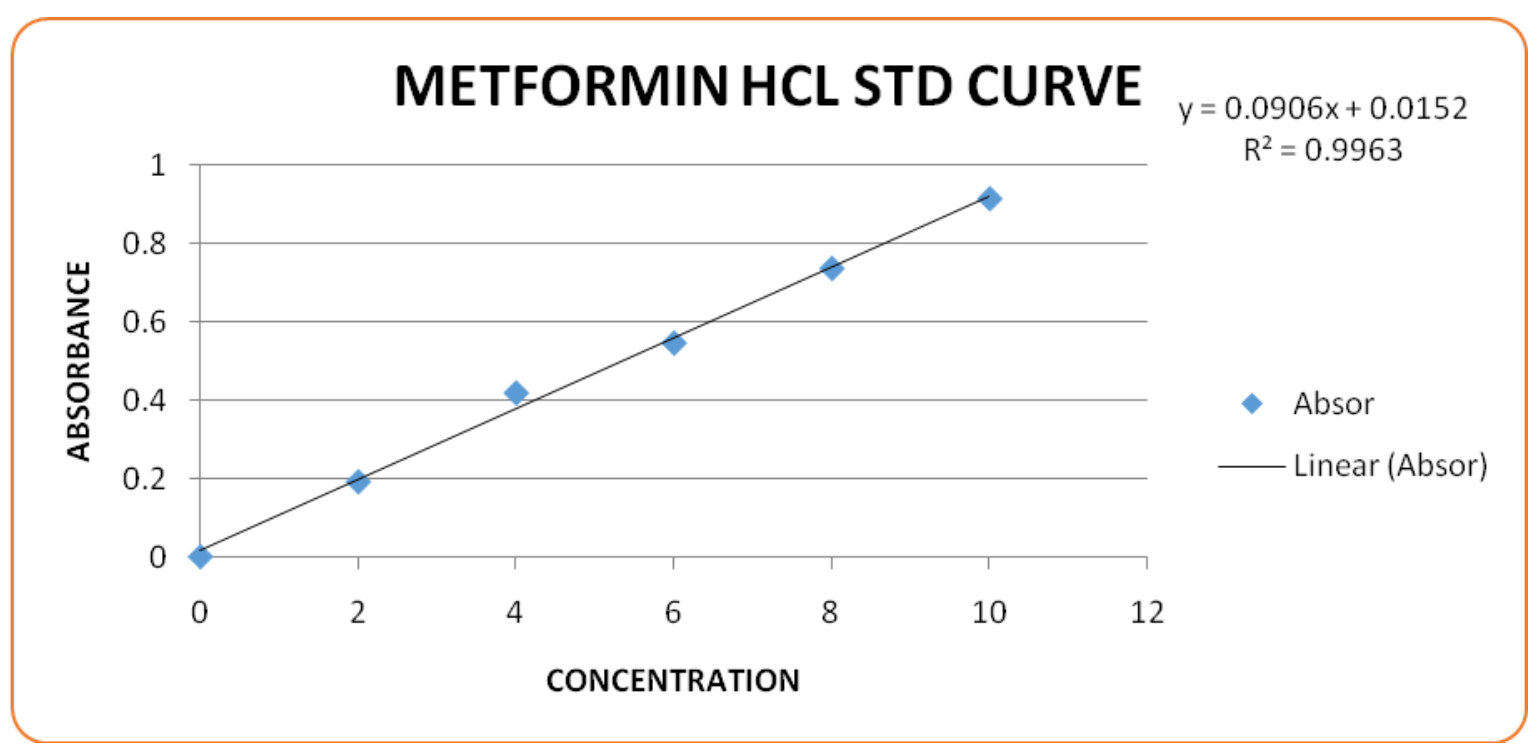

\section{Pre formulation studies}

Fig - 1 Standard curve of Metformin Hcl

1. Bulk density:

a. Loose bulk density: An accurately weighed quantity of powder was transferred to a $10 \mathrm{ml}$ measuring cylinder and the volume occupied by the powder in terms of $\mathrm{ml}$ was recorded.

Loose bulk density $(\mathrm{LBD})=$ Weight of powder in gm

Volume packed in $\mathrm{ml}$

b. Tapped bulk density: Loosely packed powder in the cylinder was tapped 100 times on a plane hard surface and volume occupied in $\mathrm{ml}$ was noted.

Tapped bulk density $(\mathrm{TDB})=$ Weight of powder in gm

Tapped volume in $\mathrm{ml}$

2. Hausner's ratio: It is the number that is related to the flowability of powder or granules. A Hausner's ratio of $<1.25$ indicates a powder that is free flowing whereas $>1.25$ indicates poor flow ability ${ }^{7}$.

3.

$$
\text { Hausner's ratio }=\mathrm{TDB} / \mathrm{LDB}(3)
$$

4. Carr's compressibility index: It is an indication of the compressibility of a granule or powder. In pharmaceutics it is an indication of flowability of powder. A Carr's index with value more than 25 is considered to be an indication of low flowability and less than 25 is having good flow property. The smaller the Carr's Index the better the flow properties. For example 5-15 indicates excellent, 12-16 good, 18-21 fair and > 23 poor flow.

$$
\text { Carr's index }(\%)=[(\mathrm{TBD}-\mathrm{LBD}) \times 100] \div \mathrm{TDB}(4)
$$

5. Angle of repose ${ }^{10}$ : A funnel is fixed and is secured with its tip at a height (h) of $2 \mathrm{~cm}$ above graph paper which is placed on a horizontal surface. The powder is dropped and the radius ( $r$ ) is measured. Values $\leq$ 30 indicates free flowing powder and $\leq 40$ are poor flowing powders. Angle of repose can be measured by the following equation ${ }^{8,10}$

$$
\Theta=\tan ^{-1}(\mathrm{~h} / \mathrm{r}) \text { or Tan } \Theta=h / \mathrm{r}(5)
$$


Table 3 Physical properties of formulation F1 - F14

\begin{tabular}{|c|c|c|c|c|c|}
\hline SI.No & LBD & TBD & Hausner's Factor & Carr's compressibility Index & Angle of repose \\
\hline F1 & 0.4244 & 0.5345 & 1.26 & 20.60 & $21.59 \pm 0.012$ \\
\hline F2 & 0.4156 & 0.5126 & 1.23 & 18.92 & $23.52 \pm 0.013$ \\
\hline F3 & 0.4136 & 0.5164 & 1.25 & 19.91 & $26.37 \pm 0.021$ \\
\hline F4 & 0.4247 & 0.5135 & 1.21 & 17.29 & $22.74 \pm 0.026$ \\
\hline F5 & 0.4275 & 0.5274 & 1.23 & 18.94 & $23.93 \pm 0.069$ \\
\hline F6 & 0.4172 & 0.5164 & 1.24 & 19.21 & $25.49 \pm 0.010$ \\
\hline F7 & 0.4225 & 0.5203 & 1.23 & 18.80 & $21.73 \pm 0.040$ \\
\hline F8 & 0.4394 & 0.5428 & 1.24 & 19.05 & $25.30 \pm 0.062$ \\
\hline F9 & 0.4199 & 0.5194 & 1.24 & 19.16 & $22.38 \pm 0.042$ \\
\hline F10 & 0.4291 & 0.5273 & 1.23 & 18.62 & $24.28 \pm 0.064$ \\
\hline F11 & 0.4315 & 0.5349 & 1.24 & 19.33 & $22.66 \pm 0.055$ \\
\hline F12 & 0.4174 & 0.5158 & 1.24 & 19.08 & $25.44 \pm 0.028$ \\
\hline
\end{tabular}

Evaluation of physical properties of matrix tablets:

1. Thickness and diameter: 10 tablets were randomly picked from each batch and their thickness and diameter were measured using a calibrated dial Vernier calliper $( \pm 5 \% \text { is allowed })^{8,10}$.

2. Weight variation test ${ }^{1,10}: 20$ tablets were randomly selected from each batch and weighed on an electronic balance. Weight of 10 tablets and individual tablets were taken; their mean and standard deviation of weight were calculated from each batch and shown in table (2)

3. Hardness test: 10 tablets randomly selected from each batch and hardness of each tablet was determined by using a Pfizer type hardness tester ${ }^{1,9,10}$. A mean of standard deviation was calculated for each batch and is shown in table 2.

4. Friability test: It is the ability of tablets to withstand mechanical shocks during handling and transportation. 10 tablets were selected randomly from each batch and weighed and placed in a friability test apparatus and operated at a speed of $25 \mathrm{rpm}$ for 4 minutes ${ }^{10}$. Tablets were collected and weighed again. The loss of tablet weight was calculated and measured in terms of $\%$ friability. Acceptable value of friability is less than 1 . The percentage friability of prepared tablets are shown in table 2 .

$$
\mathrm{F}=\left[\left(\mathrm{W}_{\text {INITIAL }}-\mathrm{W}_{\text {FINAL }}\right) \times 100\right] \div \mathrm{W}_{\text {INITIAL }}(6)
$$

5. Disintegration test: this test is performed as per official pharmacopoeial method. The tablets didn't disintegrate but swelled and formed a gel type mass.

6. Swelling index of matrix tablets: The swelling property of matrix tablets was measured in terms of percentage weight gain by the tablet. The swelling behaviour of all formulations were studied. One tablet from each formulation was kept in a petridish containing $\mathrm{pH} 7.4$ phosphate buffer. At the end of $0.5 \mathrm{hr}$ and $1 \mathrm{hr}$, the tablet was withdrawn and soaked with tissue paper, then weighed. Then after each hour weight of tablets are weighed and continued till 8hrs. percentage weight gain of tablets were calculated by the formula

$$
\text { S.I }=\left\{\left(M_{t}-M_{o}\right) / M_{o}\right\} \times 100(7)
$$

Where, S.I = swelling index, Mt = weight of tablet at time $\mathrm{t}(\mathrm{h}), \mathrm{Mo}=$ weight of tablet at zero time.

7. Drug content estimation:

a) Standard solution: $100 \mathrm{mg}$ of pure Metformin HCL drug was dissolved in water in a volumetric flask and the volume was made up to the mark and sonicated for 5 minutes.

b) Sample solution: 20 tablets from each batch were randomly selected and weighed accurately and finely powdered. To a powder equivalent to $100 \mathrm{mg}$ of Metformin HCL about $70 \mathrm{ml}$ of water was added and dissolved with the aid of shaker for 15 minutes; then sufficient quantity of water was added to produce $100 \mathrm{ml}$ in a volumetric flask, mixed well and filtered.

To $1 \mathrm{ml}$ of the filtrate methanol was added to produce $100 \mathrm{ml}$ and mixed well. The absorbance of a resulting solution was measured at $233 \mathrm{~nm}$ using bank as standard solution. This test was conducted in triplicate. 
Fig - 2 Swelling index of optimized formulations from F9 - F14

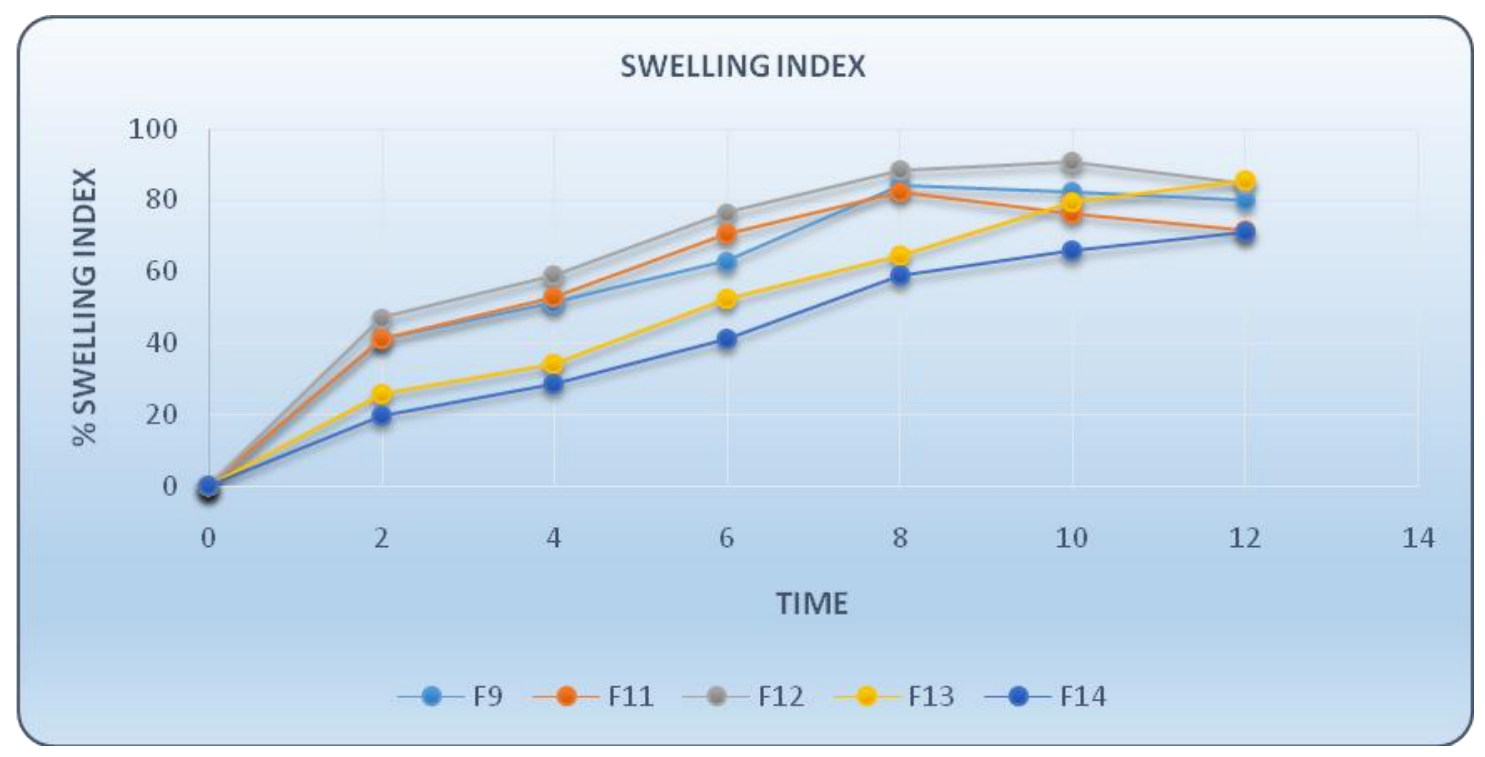

Table 4 Physical properties of formulation F1 - F14

\begin{tabular}{|c|c|c|c|c|}
\hline SI.No & Hardness & \% Friability & Weight variation & \% Drug content \\
\hline F1 & 5.23 & 0.8 & 860.54 & 99.83 \\
\hline F2 & 5.44 & 0.75 & 870.67 & 98.45 \\
\hline F3 & 5.57 & 0.64 & 854.98 & 99.38 \\
\hline F4 & 5.27 & 0.56 & 848.63 & 99.68 \\
\hline F5 & 5.47 & 0.58 & 859.3 & 97.48 \\
\hline F6 & 5.50 & 0.64 & 855.37 & 98.37 \\
\hline F7 & 5.30 & 0.65 & 851.84 & 99.25 \\
\hline F8 & 5.50 & 0.59 & 862.75 & 98.57 \\
\hline F9 & 5.50 & 0.54 & 847.85 & 99.73 \\
\hline F10 & 5.87 & 0.63 & 857.83 & 98.49 \\
\hline F11 & 5.60 & 0.68 & 860.37 & 99.28 \\
\hline F12 & 5.63 & 0.53 & 854.48 & 99.63 \\
\hline
\end{tabular}

Evaluation of granules: All the tablets of metformin HCL were prepared and valuated for the following parameters.

Friability: Previously weighed 10 tablets were taken in Roche friabilator and the friability was checked at 25 $\mathrm{rpm}$ for 4 minutes. Then the tablets were dusted and reweighed and the percentage of powder eroded during 4 minutes was recorded. The resulting tablets were weighed and the percentage loss was calculated using the formula. The results are given in table-(2).

Stability studies ${ }^{12}$ : Short-term stability studies were performed at temperature $40 \pm 2^{\circ} \mathrm{C}$ over a period of three months on the matrix tablet formulation F4. Sufficient number of tablets (ten) were packed in amber colored screw capped bottles and kept in stability chamber maintained at $40 \pm 2^{\circ} \mathrm{C}$. Samples were taken at one month intervals for drug content estimation shown in table-(7). At the end of three months period, dissolution test was performed to determine the drug release profiles. The data of dissolution after stability studies are shown in table (8). 
Table 5: Stability studies of MHF13 formulations

\begin{tabular}{|c|c|c|c|}
\hline SL.NO & TIME IN DAYS & PHYSICAL CHANGES & $40 \pm 2^{\circ} \mathrm{C}$ \\
\hline 1 & 01 & - & $98.60 \pm 1.45$ \\
\hline 2 & 30 & No Change & $97.97 \pm 1.45$ \\
\hline 3 & 60 & No Change & $97.43 \pm 0.53$ \\
\hline 4 & 90 & No Change & $96.93 \pm 0.72$ \\
\hline
\end{tabular}

Table 6: Stability study of $\mathrm{F} 13$ formulation at $40 \pm 2^{\circ} \mathrm{C}$

\begin{tabular}{|c|c|c|c|}
\hline \multirow{2}{*}{ SI.No } & Time (Hrs.) & \multicolumn{2}{|c|}{ Formulation F13 } \\
\hline $\mathbf{1}$ & 1 & $\mathbf{1}^{\text {st }} \mathbf{d a y}$ & $\mathbf{9 0}^{\text {th }} \mathbf{d a y}$ \\
\hline $\mathbf{2}$ & 2 & 20.70 & 20.58 \\
\hline $\mathbf{3}$ & 3 & 34.22 & 34.02 \\
\hline $\mathbf{4}$ & 4 & 38.74 & 38.78 \\
\hline $\mathbf{5}$ & 5 & 47.74 & 47.27 \\
\hline $\mathbf{6}$ & 6 & 60.35 & 60.43 \\
\hline $\mathbf{7}$ & 7 & 66.20 & 66.36 \\
\hline $\mathbf{8}$ & 8 & 71.17 & 71.19 \\
\hline $\mathbf{9}$ & 9 & 75.68 & 75.51 \\
\hline $\mathbf{1 0}$ & 10 & 79.28 & 79.36 \\
\hline $\mathbf{1 1}$ & 11 & 85.59 & 85.52 \\
\hline $\mathbf{1 2}$ & 12 & 89.20 & 89.02 \\
\hline
\end{tabular}

\section{RESULT AND DISCUSSION}

In the present work swelling restricted matrix tablets of Metformin HCL were prepared by direct compression method to sustain its effect by using a combination of HPMC K100M and CMC as polymer and partially coating it with cellulose acetate. The prepared tablets were evaluated for physical parameters like hardness, weight variation, friability, drug content uniformity, invitro release studies and short term stability studies ${ }^{9,11}$.

Fig 3: Invitro release data of various swelling restricted metformin HCL matrix tablets

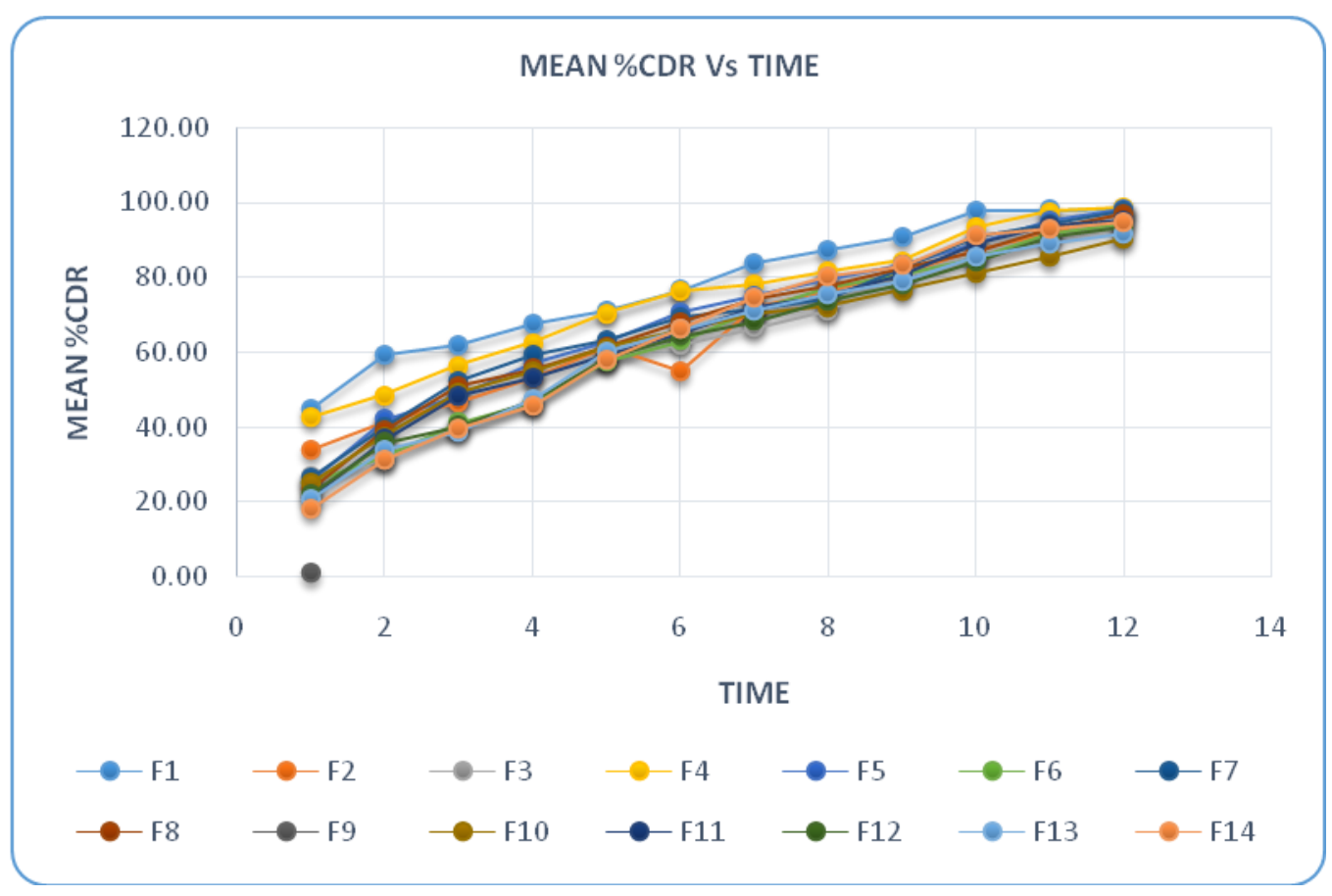


Table 7: Linear regression analysis data of Metformin HCL

\begin{tabular}{|c|c|c|c|c||c|c|c|c|}
\hline \multicolumn{9}{|c}{ Zero Order Kinetics } \\
\hline Formulation & AVG k & \pm SEM & AVG r2 & \pm SEM & AVG k & \pm SEM & AVG r2 & \pm SEM \\
\hline F1 & 4.7751 & 0.0187 & 0.9637 & 0.0014 & -0.3372 & 0.0235 & 0.8951 & 0.0085 \\
\hline F2 & 5.6638 & 0.0022 & 0.9961 & 0.0001 & -0.2394 & 0.0105 & 0.8642 & 0.0159 \\
\hline F3 & 6.3877 & 0.0069 & 0.9919 & 0.0001 & -0.2400 & 0.0122 & 0.8709 & 0.0228 \\
\hline F4 & 5.0957 & 0.0121 & 0.9788 & 0.0007 & -0.3068 & 0.0215 & 0.8537 & 0.0169 \\
\hline F5 & 6.1117 & 0.0100 & 0.9685 & 0.0005 & -0.2900 & 0.0169 & 0.8588 & 0.0220 \\
\hline F6 & 6.4548 & 0.0096 & 0.9845 & 0.0002 & -0.2262 & 0.0079 & 0.9484 & 0.0061 \\
\hline F7 & 5.9096 & 0.0047 & 0.9635 & 0.0003 & -0.2679 & 0.0144 & 0.8669 & 0.0159 \\
\hline F8 & 6.0788 & 0.0027 & 0.9619 & 0.0005 & -0.2519 & 0.0115 & 0.8985 & 0.0128 \\
\hline F9 & 5.9328 & 0.0215 & 0.9638 & 0.0004 & -0.1673 & 0.0048 & 0.9762 & 0.0051 \\
\hline F10 & 5.2974 & 0.0101 & 0.9507 & 0.0007 & -0.1634 & 0.0040 & 0.9699 & 0.0026 \\
\hline F11 & 6.3020 & 0.0018 & 0.9698 & 0.0003 & -0.2406 & 0.0092 & 0.9281 & 0.0060 \\
\hline F12 & 6.2578 & 0.0044 & 0.9810 & 0.0007 & -0.2106 & 0.0056 & 0.9403 & 0.0039 \\
\hline F13 & 6.3349 & 0.0138 & 0.9632 & 0.0002 & -0.2014 & 0.0057 & 0.9800 & 0.0028 \\
\hline F14 & 7.0509 & 0.0079 & 0.9647 & 0.0008 & -0.2537 & 0.0101 & 0.9683 & 0.0050 \\
\hline
\end{tabular}

Table 7: Linear regression analysis data of Metformin HCL

\begin{tabular}{|c|c|c|c|c|c|c|c|c|}
\hline \multicolumn{5}{|c|}{ Higuchi Model } & \multicolumn{4}{|c|}{ Peppas Model } \\
\hline Formulation & AVG k & $\pm \mathrm{SEM}$ & AVG r2 & \pm SEM & AVG n & $\pm \mathrm{SEM}$ & AVG r2 & \pm SEM \\
\hline F1 & 0.222 & 0.001 & 0.985 & 0.0018 & 0.319 & 0.002 & 0.982 & 0.0024 \\
\hline F2 & 0.261 & 0.000 & 0.988 & 0.0000 & 0.437 & 0.005 & 0.979 & 0.0003 \\
\hline F3 & 0.294 & 0.000 & 0.984 & 0.0005 & 0.546 & 0.007 & 0.977 & 0.0009 \\
\hline F4 & 0.237 & 0.001 & 0.989 & 0.0002 & 0.357 & 0.003 & 0.980 & 0.0005 \\
\hline F5 & 0.286 & 0.000 & 0.997 & 0.0001 & 0.520 & 0.007 & 0.994 & 0.0005 \\
\hline F6 & 0.299 & 0.000 & 0.992 & 0.0001 & 0.568 & 0.007 & 0.990 & 0.0004 \\
\hline F7 & 0.276 & 0.000 & 0.987 & 0.0007 & 0.500 & 0.006 & 0.989 & 0.0005 \\
\hline F8 & 0.285 & 0.000 & 0.995 & 0.0002 & 0.542 & 0.008 & 0.988 & 0.0010 \\
\hline F9 & 0.278 & 0.001 & 0.991 & 0.0003 & 0.580 & 0.006 & 0.990 & 0.0001 \\
\hline F10 & 0.250 & 0.000 & 0.991 & 0.0003 & 0.492 & 0.007 & 0.990 & 0.0002 \\
\hline F11 & 0.295 & 0.000 & 0.994 & 0.0002 & 0.576 & 0.009 & 0.989 & 0.0007 \\
\hline F12 & 0.291 & 0.000 & 0.994 & 0.0001 & 0.572 & 0.009 & 0.993 & 0.0002 \\
\hline F13 & 0.297 & 0.001 & 0.993 & 0.0001 & 0.604 & 0.006 & 0.992 & 0.0002 \\
\hline F14 & 0.330 & 0.000 & 0.991 & 0.0003 & 0.677 & 0.010 & 0.994 & 0.0004 \\
\hline
\end{tabular}

Fig 4: Percentage drug release Vs Time of formulation F1 - F14

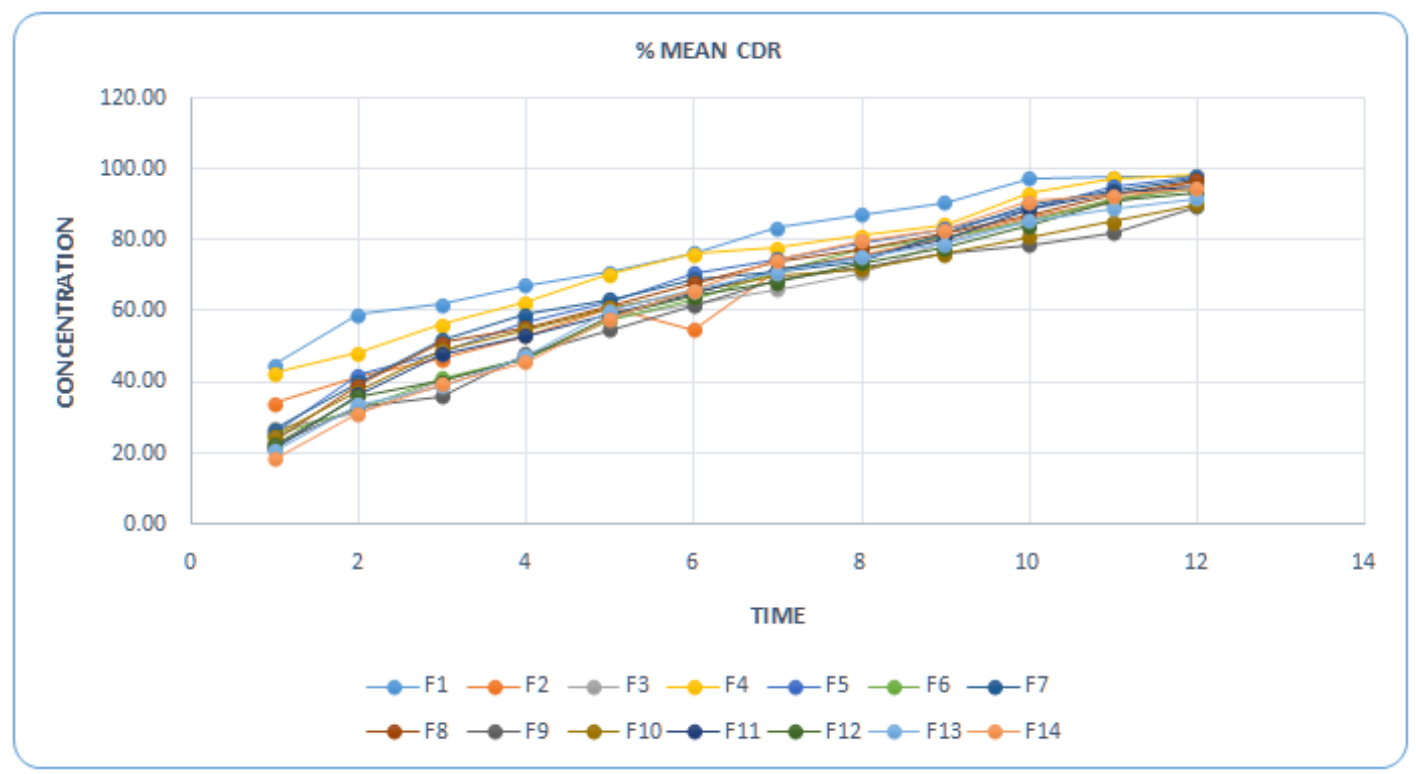


Fig 5: Log Cumulative drug to be released Vs Time of formulation F1 - F14

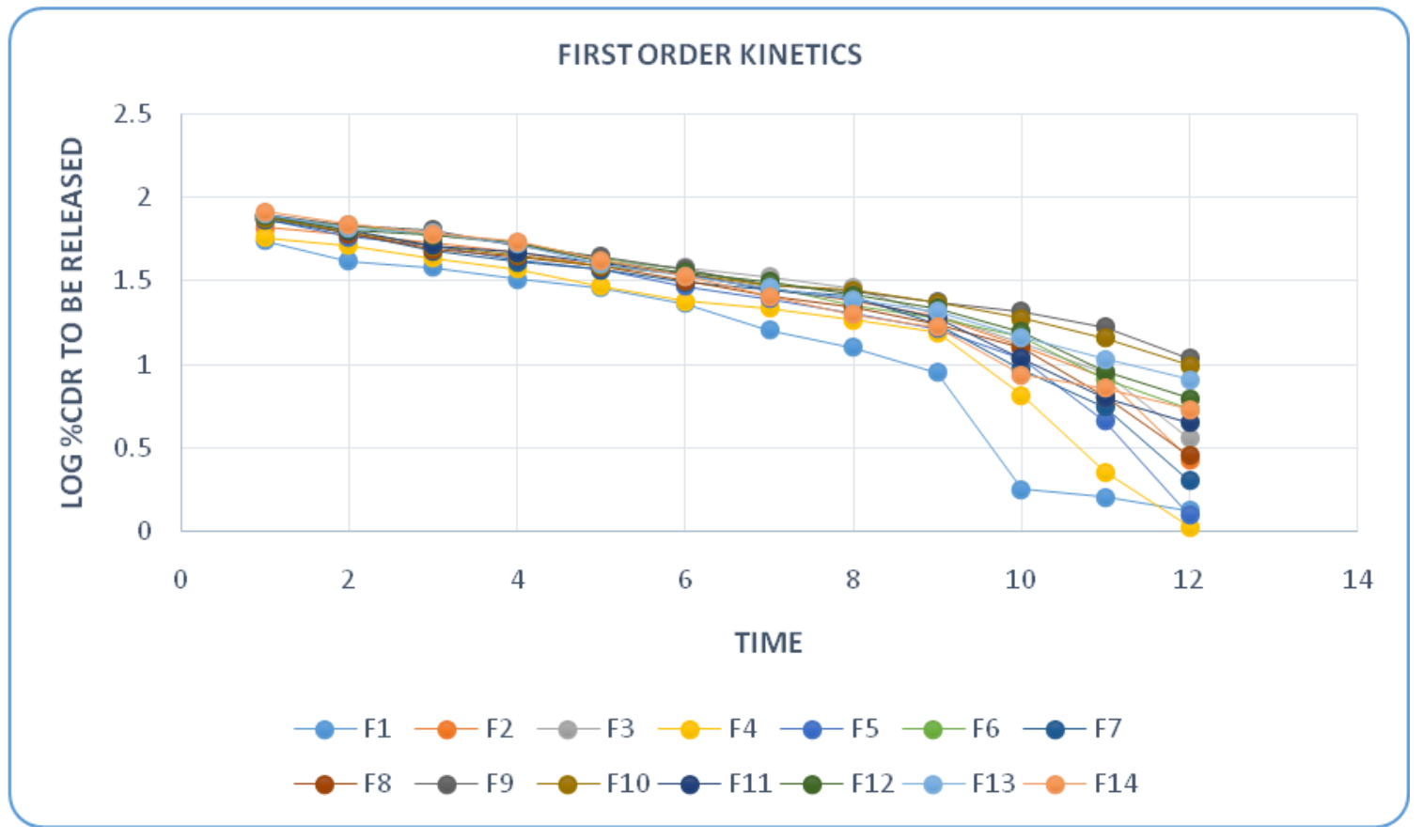

Fig 6: Cumulative \% drug release Vs square root time of formulation F1 - F14

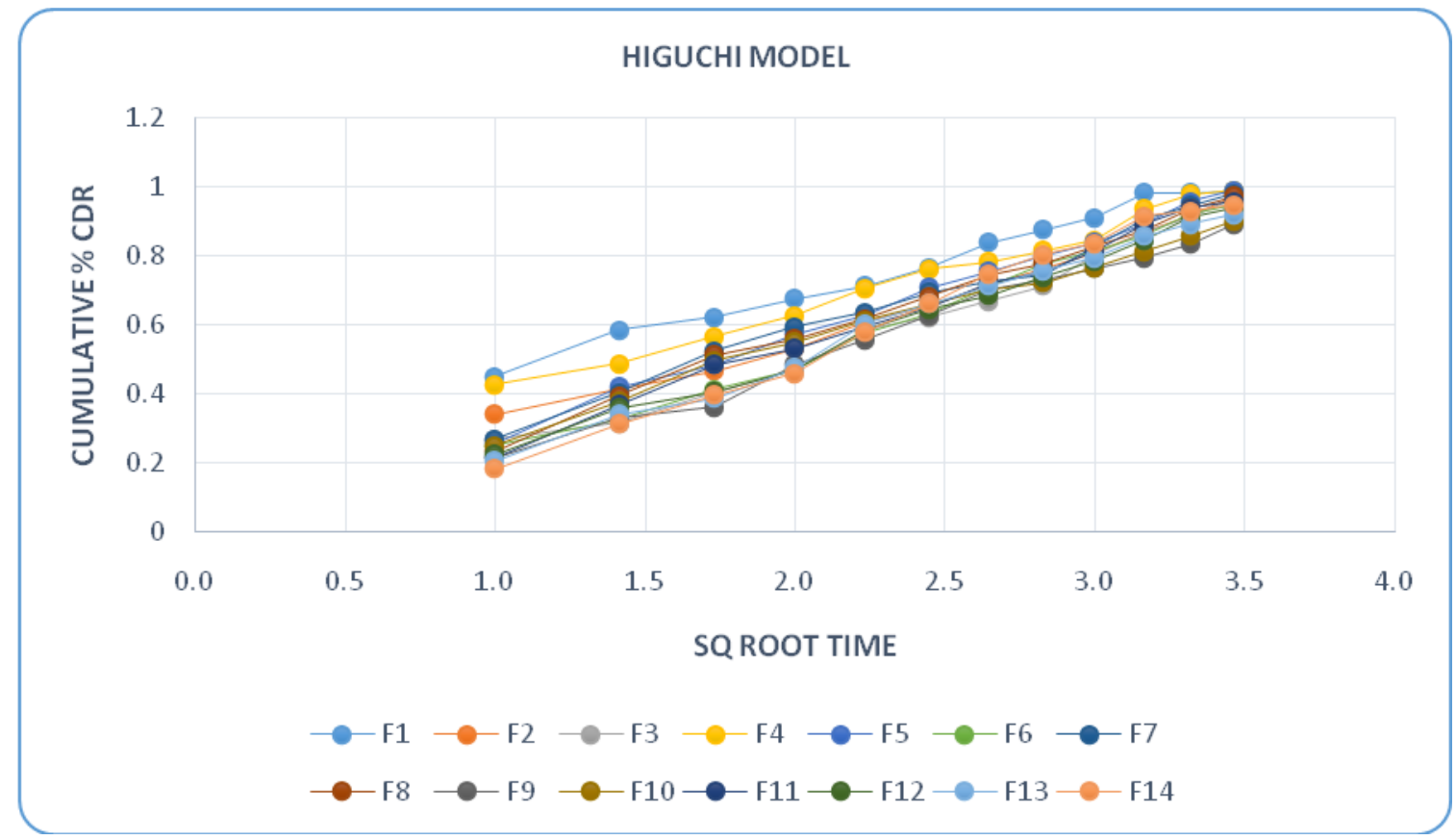


Fig 7: Log cumulative drug released vs Log time of formulation F1 - F14

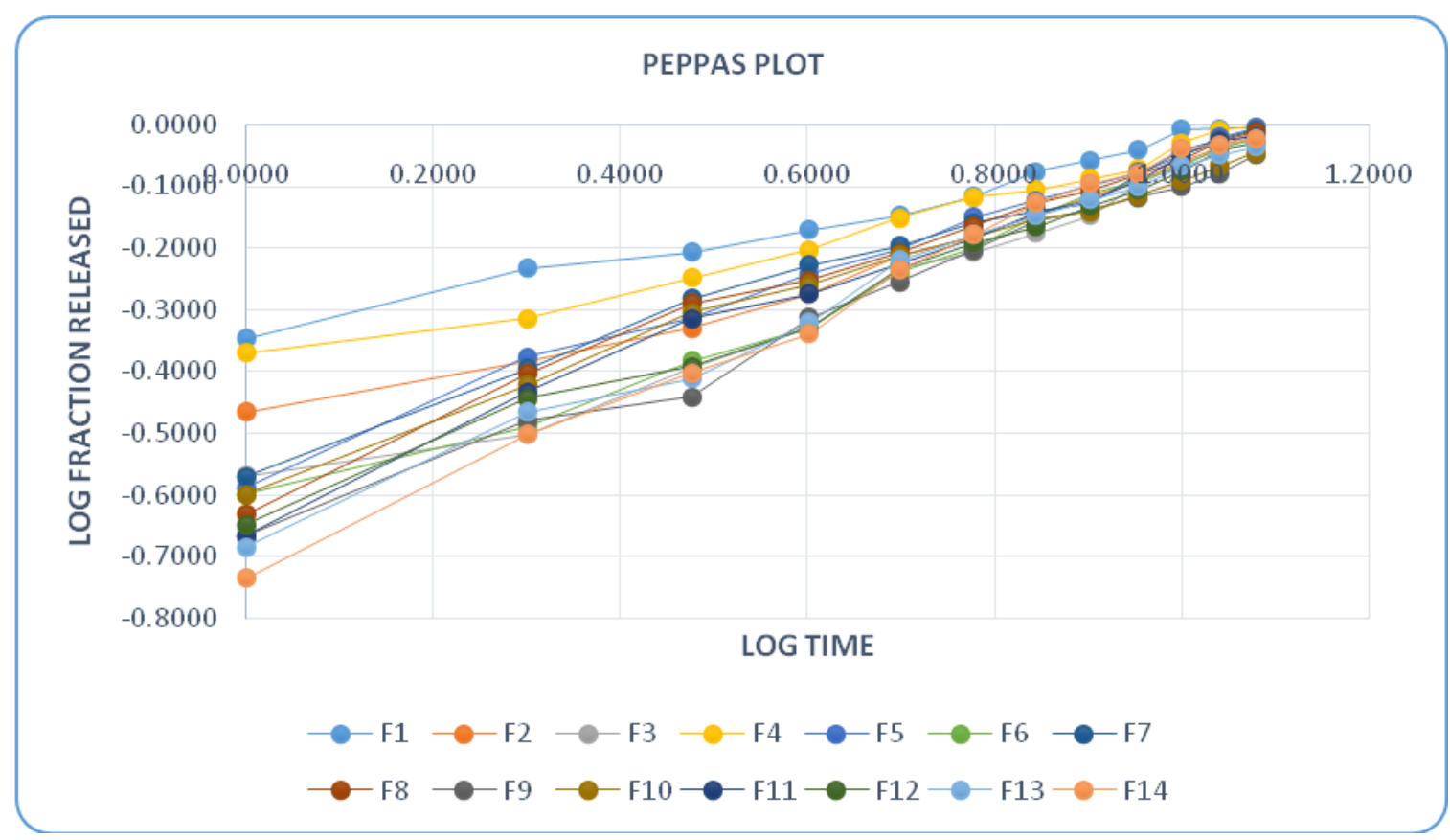

Fig 8: In-Vitro drug release profile for stability of formulation F13 at $40 \pm 2{ }^{\circ} \mathrm{C}$

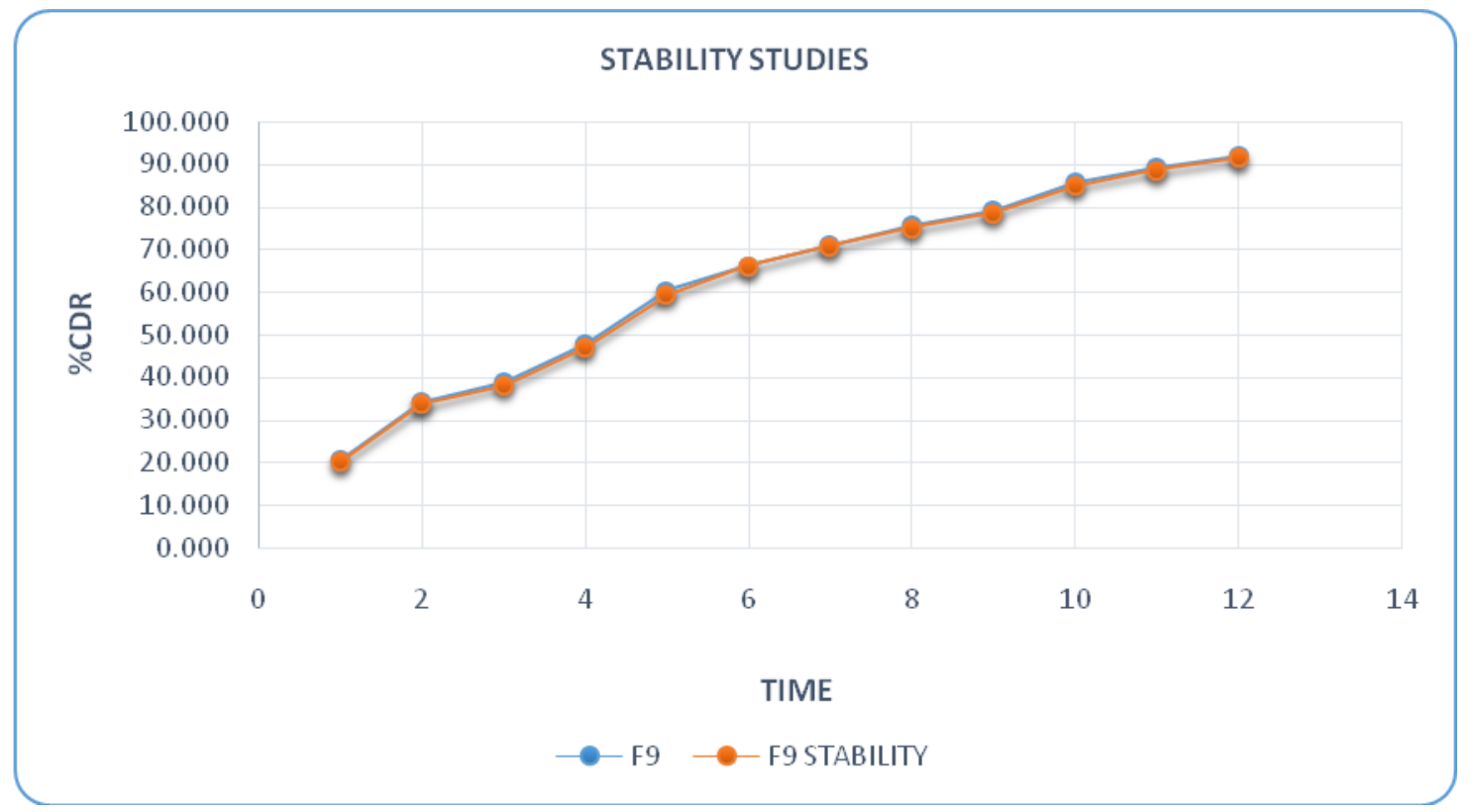

All the prepared tablets were evaluated for weight variation and the results are given in table 2 . The percentage deviation from the average weight was found to be within the prescribed official limits.

Hardness of tablets were found to be in the range of $5.23-5.87 \mathrm{~kg} / \mathrm{cm}^{2}$ which is given in table 2 . The friability of all prepared tablets were found to be in the range of $0.53-0.80 \%$ which fulfils the official requirements (less than $1 \%)^{13,14,15 .}$

Drug content estimation data for all batches are given in table 2. It was found to be in the range of 98.37 - 99.83 which indicates uniform drug content in the tablets prepared. 
Invitro release studies of prepared matrix tablets were conducted for a period of $12 \mathrm{hrs}$. Using an eight station USP XXII type 2 apparatus at $37 \pm 0.5^{\circ} \mathrm{C}$, speed of basket was set at $100 \pm 1 \mathrm{rpm}$. In each flask $900 \mathrm{ml}$ buffered to a $\mathrm{pH} 6.8$ was used as dissolution media.

$5 \mathrm{ml}$ samples were withdrawn at $1 \mathrm{hr}$. interval and replaced with fresh medium to maintain sink condition. Sample was filtered and diluted appropriately, analysed at $233 \mathrm{~nm}$ by double beam UV / visible spectrophotometer using dissolution medium as blank. Experiments were performed in triplicate. The amount of drug present in the samples was calculated by using calibration curve constructed from reference standard. Dissolution data of the matrix tablets were plotted and in vitro drug release data was subjected to goodness of fit test by linear regression analysis according to zero order, first order, kinetic equations like Higuchi and Peppas models in order to determine the mechanism of drug release. The results of linear regression analysis of data including regression coefficients are summarized in table-6.

The release of drug from the formulations containing HPMC K100M and CMC were found to be governed by diffusion controlled process, since the $r$ values for Higuchi's plot were found to be in the range of 0.98 and 0.99 . When the data's were treated according to Peppas equation, the release exponents (n values) for most of the formulations was found to be $0.31<\mathrm{n}<0.67$ indicating non-Fickian release mechanism. Although the drug release data fitted better to anomalous (non-Fickian) diffusion mechanism, a model representing zero order was also very close ( $r=0.99$ for formulations F5, F6, F9, F10, F12 - F14).

Short-term stability studies were performed for the best formulation $\mathrm{F} 13$ at $40 \pm 2^{\circ} \mathrm{C}$ for three months ( 90 days). The samples were analysed for percent drug content and in vitro drug release studies. The results are given in table-7 and 8 . No appreciable difference were observed for the above parameters.

\section{CONCLUSION}

From the present study the following conclusions were made:

- Matrix tablets of metformin Hcl using HPMC (K4M, K15M, and K100M) and CMC prepared by direct compression method were found to be good without chipping, capping and sticking.

- The drug content was uniform in all the formulations of tablets prepared. Low values of standard deviations indicates uniform distribution of drugs within the matrices.

- The drug polymer ration influenced the release of drug from the formulations. An increase in polymer decreased the drug release. F13 partially coated swelling matrix tablet further retarded the release of drug.

- Formulation F13 with drug polymer (HPMC K100M and CMC) ratio (500:125:125) has shown promising results as per USP test I requirements.

- Swelling restricted matrix tablets of Metformin Hcl were prepared using HPMC K100M and CMC to achieve desired release rates over a period of 12 hours, which can help to reduce the dose and its frequency.

- Among these formulations F13 is acceptable for further pharmacodynamic and pharmacokinetic evaluation

\section{REFERENCES}

[1]. Brahmankar HA, Jaiswal SB, "Bio pharmaceutics and Pharmacokinetics A Treatise",(Vallabh Prakashan, 2009 Reprint Edition), 348-357 and 337 .

[2]. $\quad$ Robinson JR, Lee HL (Ed), Controlled Drug Delivery: Fundamentals \& Applications, 2nd Edition, (Marcel Dekker Inc, New York, 1987), 373

[3]. Kumar Kiran S., Rao Rama T, Jayaveera K.N, "Matrix Tablets as Controlled drug delivery systems", Indo American Journal of Pharmaceutical Research, 1(4),2011,343-350.

[4]. Loyd V. Allen. Jr, Nicholas G. Popvich, Howard C. Ansel, "Pharmaceutical dosage forms and drug delivery system", 8th edition, 260-263.

[5]. Sweetman SC, Martindale, The Complete Drug Reference,33rd Ed,(Pharmaceutical Press 2002),962.

[6]. Patel Harnish, Panchal Dhrupesh R., Patel Upendra, Brahmbhatt Tushar,, Suthar Mayur, "Matrix Type Drug Delivery System: A Review", Journal of Pharmaceutical Science and Bioscientific Research"; 1(3), Nov-Dec 2011,143-151.

[7]. Shargel L, Yu Andrew B.C., Wu-Pong Susanna, "Modified release drug products", Applied Bio pharmaceutics and Pharmacokinetics, 5th Edition,( McGraw Hill, 1999), 170-173.

[8]. Siepmann J, Peppas NA, HPMC matrices for controlled drug delivery: new model combining diffusion, swelling and dissolution mechanisms and predicting the release kinetics, Pharm Research, 2000, 1748-1756.

[9]. Adulkarim K Al Zomor, Khalid M Al akhaly, Evaluation of drug release kinetics for diclofenac sodium 100mg origin brand Matrix tablet, Asian journal of pharmacy and life science , 2 (2),2012.

[10]. Lachmann L, Lieberman HA, Kanig JL, The Theory \& Practice of Industrial Pharmacy.( Varghese Publishing House, Bombay), $3^{\text {rd }}$ Edition, 1991, 430.

[11]. Borguist P, Korner A, Larsson A, A model for the drug release from a polymeric matrix tablets-effect of swelling and dissolution, J Controlled Release ,113,2006, 216-17

[12]. Gennaro AR (Ed.) Remington, The Science \& Practice of Pharmacy, $19^{\text {th }}$ Edition, Vol. II, 1995, 1662.

[13]. Herbert A, Lieberman \& Leon Lachman, Pharmaceutical Dosage Forms: Tablets, Vol. III,(Marcel Dekker Inc, New York), 9-10.

[14]. The United States Pharmacopoeial Convention Inc, CD-2004, USP27-NF-22.

[15]. INDIAN PHARMACOPOEIA, 4. Ed,( New Delhi: The Controller of Publications), 1996a, 1,.470.

[16]. Saraiya D, Bolton S. The use of precirol to prepare sustained release tablet of theophylline and quinidine gluconate. Drug Dev Ind Pharm 1990; 16: 1963-1969. 